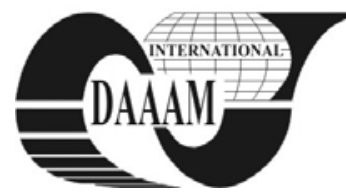

Annals of DAAAM for 2011 \& Proceedings of the 22nd International DAAAM Symposium, Volume 22, No. 1, ISSN 1726-9679 ISBN 978-3-901509-83-4, Editor B. Katalinic, Published by DAAAM International, Vienna, Austria, EU, 2011 Make Harmony between Technology and Nature, and Your Mind will Fly Free as a Bird Annals \& Proceedings of DAAAM International 2011

\title{
INVESTIGATION OF STRESSES IN TEETH PREPARED WITH DIFFERENT TAPERS AND RESTORED WITH CAST CROWNS
}

\author{
SANDU, L[iliana]; TOPALA, F[lorin] I[onel] \& POROJAN, S[orin]
}

\begin{abstract}
The objective of this study was to evaluate, using a simulated model experiment, the influence of different degree of taper for complete gold cast crown preparations, on the stress distribution in teeth and overlying crowns. A $3 D$ model of an upper first molar was obtained by $3 D$ scanning. The tooth preparations with different tapers and chamfer shoulder, together with the complete cast crowns were designed. Models were exported in a finite element analysis software for structural simulations. In the prepared teeth the taper was important both for the stress values and distribution. The best advisable taper from biomechanical point of view for complete gold cast crowns is 5 degree.
\end{abstract}

Key words: taper, complete cast crown, 3D model, finite element analysis, stress

\section{INTRODUCTION}

In order to function for a long term, it is necessary to ensure that complete crowns possess high mechanical strength (Suzuki et al., 2009). The form of prepared teeth and the amount of tooth structure removed are important contributors to the mechanical, biologic and esthetic success of the overlying crown (Shekar et al., 2010). A complete cast crown preparation has a good resistance form if the axial walls have been prepared with the proper degree of taper or convergence. The strength of a complete cast crown is superior to that of other prosthetic restorations. The margin should have a chamfer configuration, be smooth and distinct and its width should be approximately $0.5 \mathrm{~mm}$, which will allow adequate bulk of metal at the margin (Rosenstiel et al., 2001). The fit of cast denture restoration is essential because it may influence the thickness of the cement margin, periodontal soundness, and the risk of secondary caries, which are decisive factors accounting for the clinical success of restorations (Rocha et al., 2007). Over the past decades, the search for dental materials of good quality and safe to patient's health has increased significantly. Biosafety has become a key factor for the choice of gold alloys (Soriani et al., 2007).

\section{AIM}

The objective of this study was to evaluate, using a simulated model experiment, the influence of different degree of taper for complete gold cast crown preparations, on the stress distribution in teeth and overlying crowns.

\section{MATERIALS AND METHOD}

A 3D model of an upper first molar was created: intact tooth, unrestored teeth with different tapers, that include theoretically zero or parallel degree to clinically obtained 10 degree of the axial walls, and chamfer marginal geometry. The same prepared teeth were modeled restored with complete cast gold crowns.

The geometry of the intact tooth were obtained by 3D scanning using a manufactured device.
The nonparametric modeling software (Blender 2.57b) was used to obtain the shape of the tooth structures. The collected data were used to construct three dimensional models using Rhinoceros (McNeel North America) NURBS (Nonuniform Rational B-Splines) modeling program (Fig. 1, 2).

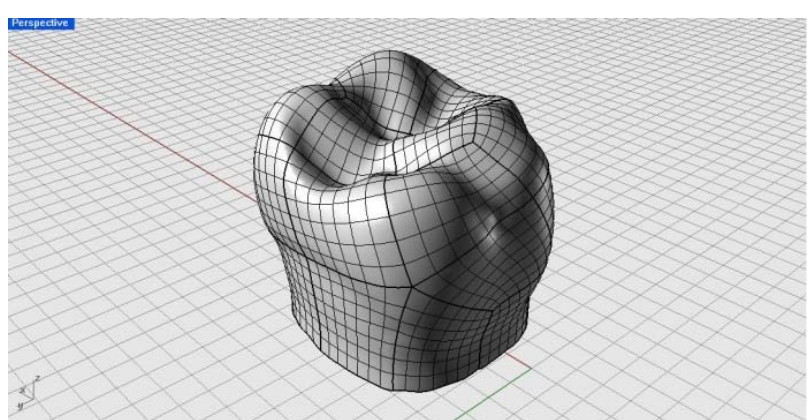

Fig. 1. 3D model of the intact molar after NURBS modeling.

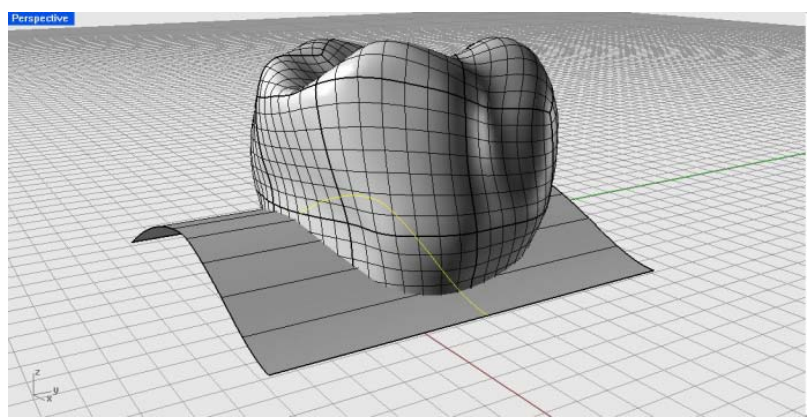

Fig. 2. Marking of the cervical line and preparation limit.

The tooth preparations with different tapers and chamfer shoulder, together with the complete cast crowns were designed (Fig. 3).

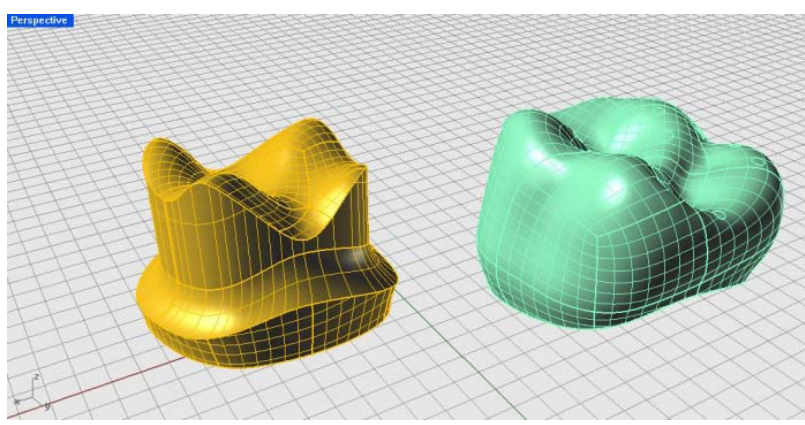

Fig. 3. 3D models of the prepared tooth and the overlying complete crown.

Models were exported in Ansys finite element analysis software for structural simulations (Fig. 4). An occlusal load of $200 \mathrm{~N}$ was applied in 10 points, according to the contact points with the antagonists. The forces were applied perpendicular to 
the tooth surface in each point. The mesh structure of the solid 3D model was created using the computational simulation of Ansys finite element analysis software (Fig. 5).

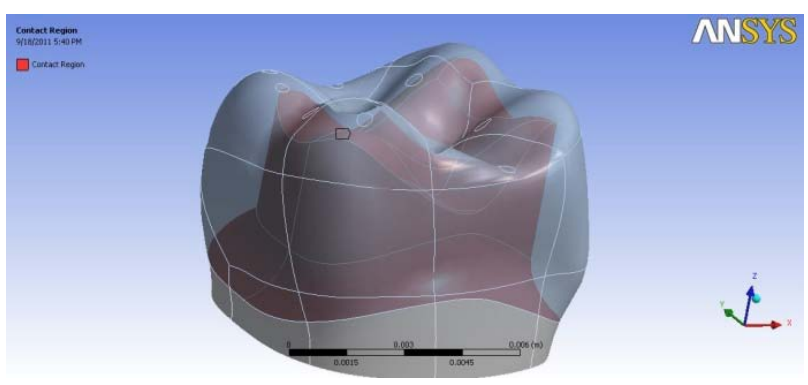

Fig. 4. 3D model in the finite element analysis software.

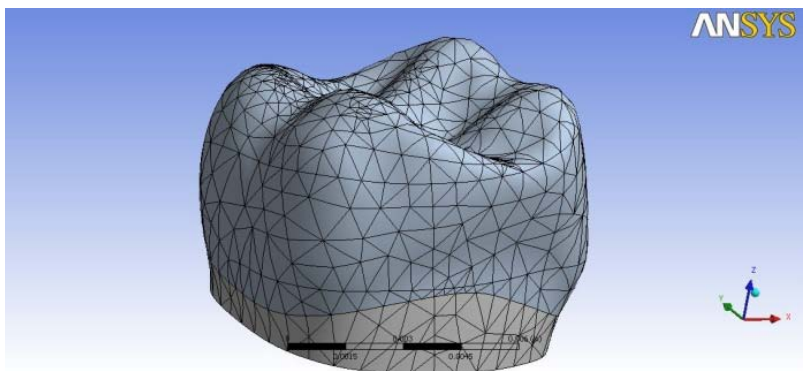

Fig. 5. Mesh structure of the restored molar.

Von Mises equivalent stresses were calculated and their distribution was plotted graphically.

\section{RESULTS AND DISCUSSIONS}

The study was conducted to evaluate the stresses in the prepared teeth with various degree tapers (between 0 and 10 degree) and of complete gold cast crowns, and to draw general guidelines about the best advisable taper from biomechanical point of view.

Higher values of the maximal equivalent stress (1.17-1.32 $\mathrm{x}$ $10^{2} \mathrm{MPa}$ ) were present in the crowns, distributed on the occlusal surface around the contact points with the antagonists (Fig. 6), with no significant differences between the preparation tapers. In the prepared teeth the taper was important both for the stress values and distribution. For preparations beteen 4 and 7 degree, the values were smaller than for the other cases. Also the largest stress area is present for the 5 degree taper preparation (Fig. 7), correlated with the smallest maximal stress value from all the studied cases.

\begin{tabular}{|c|c|c|c|}
\hline \multirow{2}{*}{$\begin{array}{c}\text { Degree of } \\
\text { taper }\end{array}$} & \multicolumn{3}{|c|}{ Maximal Von Mises equivalent stress [Pa] } \\
\cline { 2 - 4 } & total & crown & $\begin{array}{c}\text { prepared } \\
\text { tooth }\end{array}$ \\
\hline 0 & $1.17 \mathrm{E}+08$ & $1.17 \mathrm{E}+08$ & $1.40 \mathrm{E}+07$ \\
\hline 1 & $1.31 \mathrm{E}+08$ & $1.31 \mathrm{E}+08$ & $1.42 \mathrm{E}+07$ \\
\hline 2 & $1.32 \mathrm{E}+08$ & $1.32 \mathrm{E}+08$ & $1.31 \mathrm{E}+07$ \\
\hline 3 & $1.27 \mathrm{E}+08$ & $1.27 \mathrm{E}+08$ & $1.38 \mathrm{E}+07$ \\
\hline 4 & $1.32 \mathrm{E}+08$ & $1.32 \mathrm{E}+08$ & $1.26 \mathrm{E}+07$ \\
\hline 5 & $1.21 \mathrm{E}+08$ & $1.21 \mathrm{E}+08$ & $1.11 \mathrm{E}+07$ \\
\hline 6 & $1.17 \mathrm{E}+08$ & $1.17 \mathrm{E}+08$ & $1.21 \mathrm{E}+07$ \\
\hline 7 & $1.20 \mathrm{E}+08$ & $1.20 \mathrm{E}+08$ & $1.29 \mathrm{E}+07$ \\
\hline 8 & $1.18 \mathrm{E}+08$ & $1.18 \mathrm{E}+08$ & $1.46 \mathrm{E}+07$ \\
\hline 9 & $1.21 \mathrm{E}+08$ & $1.21 \mathrm{E}+08$ & $1.51 \mathrm{E}+07$ \\
\hline 10 & $1.17 \mathrm{E}+08$ & $1.17 \mathrm{E}+08$ & $1.40 \mathrm{E}+07$ \\
\hline
\end{tabular}

Tab. 1. Maximal Von Mises equivalent stress values in the cast crowns and in the restored molars.

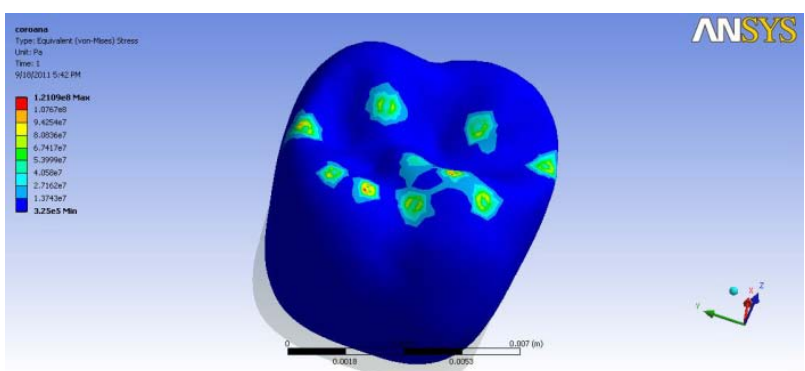

Fig. 6. Von Mises equivalent stress in the cast crown (preparation taper of 5 degree).

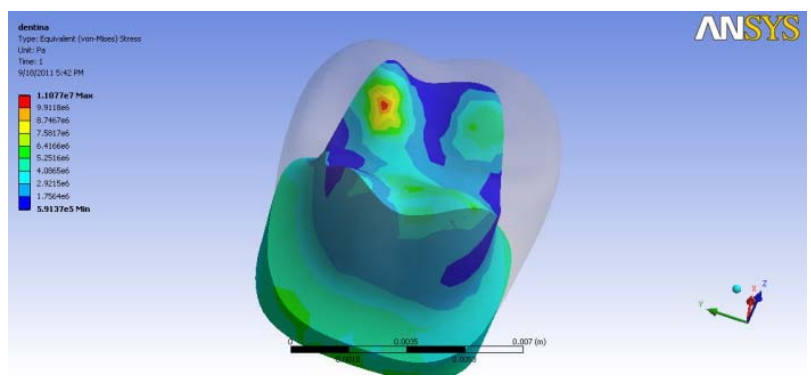

Fig. 7. Von Mises equivalent stress in the restored teeth (preparation taper of 5 degree).

\section{CONCLUSIONS}

Within the limitations of the present study the following conclusions can be drawn:

1. The preparation taper of the axial walls for complete cast crowns is important both for the stress values and distribution in the prepared teeth.

2. The best advisable taper from biomechanical point of view for complete gold cast crowns is 5 degree. Clinically obtained 4 to7 degree of the axial walls should satisfy biomechanically requirements.

3. Further research could correlate these results with other points of view regarding the preparation design for complete cast crowns.

\section{ACKNOWLEDGEMENTS}

This work was supported by CNCSIS-UEFISCSU, project number PN II-RU TE_217/2010.

\section{REFERENCES}

Suzuki, C.; Miura, H.; Okada, D.; Komada, W.; Miyasaka, M.; Yamamoto, M. \& Masuoka, D. (2009). Investigation of distortions around the cervical area of teeth restored with two kinds of crown materials. Dent Mater J, 28(2): 142-52, ISSN 0287-4547

Shekar, S. C.; Giridhar, K. \& Rao, K.S. An In Vitro Study to Evaluate the Retention of Complete Crowns Prepared with Five Different Tapers and Luted with Two Different Cements. J Indian Prosthodont Soc, 10(2):89-95, ISSN 0972-4052

Rosenstiel, S.; Land, M. \& Fujimoto, J. (2001). Contemporary fixed prosthodontics, 3rd ed., 1-868, Mosby, ISBN 0-81515559-X, St. Louis

Rocha, S. S.; Adabo, G. L.; Ribeiro, R. F. \& Fonseca, R. G. (2007). Internal adaptation of cast titanium crowns. J Appl Oral Sci,15(4):247-52, ISSN 1678-7757

Soriani N. C.; Leal M. B.; Paulino, S. M.; Pagnano, V. O. \& Bezzon, O. L. (2007). Effect of the Use of Die Spacer on the Marginal Fit of Copings Cast in NiCr, NiCrBe and Commercially Pure Titanium. Braz Dent J,18(3): 225-230, ISSN 0103-6440 